\title{
Resíduos de agrotóxicos em alimentos: preocupação ambiental e de saúde para população paraibana
}

\section{Pesticide residues in food: environmental concerns and health requirements for paraibana population}

\author{
Luara Lourenço Ismael ${ }^{(1)}$, Elisângela $M^{a}$ Rodrigues Rocha ${ }^{(2)}$, Luciano Alberto Lins Filho $^{(3)}$, Raquel Patrícia Ataíde Lima ${ }^{(4)}$
}

\begin{abstract}
RESUMO - O monitoramento de resíduos de agrotóxicos em alimentos vem assumindo grande importância para o alcance à segurança alimentar dos consumidores. A Paraíba é hoje um grande consumidor de legumes, verduras e frutas no Brasil, detentora de grandes áreas de diversas monoculturas. O presente trabalho visou investigar os resíduos de agrotóxicos em alimentos comercializados no Estado da Paraíba e seus impactos negativos a saúde humana. A partir de visitas feitas em parceria com a Agência Estadual de Vigilância Sanitária (AGEVISA-PB), foram coletadas 100 amostras de 15 diferentes culturas durante os anos de 2011, 2012 e 2013 em vários supermercados da Paraíba e encaminhadas a laboratórios credenciados, onde foram investigados aproximadamente 234 diferentes ingredientes ativos de agrotóxicos em alimentos. Verificou-se que de 100 amostras de alimentos analisadas, $55 \%$ possuem resíduos de agrotóxicos. Através da identificação dos possíveis riscos a saúde humana e ao meio ambiente, resultantes de níveis de agrotóxicos acima do permitido para o consumo humano, podem-se indicar medidas preventivas e mais sustentáveis que reduzam os possíveis impactos, como por exemplo: campanhas de orientação para os produtores, incentivo ao manejo ambientalmente correto do solo e fiscalizações mais rígidas junto aos comerciantes destes produtos.
\end{abstract}

Palavras-chaves - Saúde, Alimentos, Agrotóxicos, Vigilância Sanitária e Meio Ambiente.

ABSTRACT - The Monitoring of pesticide residues in food is of great importance for achieving food security of consumers. The Paraíba is now a major consumer of vegetables and fruits in Brazil, which owns large areas of several monocultures. This study aimed to investigate the pesticide residues in foods marketed in the State of Paraíba and its negative impacts on human health. From visits in partnership with the State Agency for Sanitary Surveillance (AGEVISA-PB), 100 samples of 15 different cultures were collected during the years 2011, 2012 and 2013 in various supermarkets of Paraíba and sent to accredited laboratories, where they were investigated about 234 different pesticide active ingredients in foods. It was found that 100 food samples analyzed, 55\% had pesticide residues. By identifying the possible risks to human health and the environment resulting from pesticide levels above the permitted for human consumption, can be indicated more preventive and sustainable measures to reduce the possible impacts, such as: orientation campaigns producers, encouraging environmentally friendly soil management and stricter inspections along the traders of these products.

Key words - Health, Food, Pesticides, Health Surveillance and Environment.

\footnotetext{
*Autor para correspondência

Recebido para publicação em 18/06/2015; aprovado em 30/06/2015

${ }^{1}$ Engenheira Ambiental ( UFCG), Mestranda Pós -Graduação Eng. Civil e Ambiental - UFPB, (83) 9831-1665, luara_ismael@hotmail.com

${ }^{2}$ Engenheira Sanitarista (UFPA), Prof (a) Departamento Eng. Civil e Ambiental - UFPB, elis_eng@yahoo.com.br

${ }^{3}$ Engenheiro Ambiental, Universidade Federal da Paraíba - UFPB, lucianoalberto_@ hotmail.com

${ }^{4}$ Nutricionista (UFPB), Doutoranda Pós- Graduação Ciências da Nutrição (UFPB), raquelpatriciaal@ hotmail.com
} 


\section{INTRODUÇÃO}

Com a expansão das áreas de agricultura sem o devido planejamento territorial, aumentaram-se os impactos causados pelo uso dos agrotóxicos sobre o ambiente, contribuindo assim para a poluição do ar, do solo, das águas e a intoxicação dos homens e animais.

A preocupação dos agrotóxicos nos ecossistemas e consequentemente, na saúde humana se deve principalmente pela sua mobilidade e persistência no meio ambiente, a maior parte dos agrotóxicos utilizados em lavouras são capazes de bioacumular-se em diferentes organismos e passar anos para desaparecer, elevando seu percentual tóxico e contribuindo para a contaminação de alimentos, corpos d' água e do solo (LIMA, 2010).

O impacto do uso exagerado de agrotóxicos sobre a saúde vem preocupando cada vez mais a população que desconhece a quantidade de agrotóxicos que está ingerindo. Estes atuam, diretamente, por meio do contato direto do organismo com as substâncias. Existem três principais vias responsáveis pelo impacto direto da contaminação humana: a ocupacional, que se caracteriza pela contaminação dos trabalhadores que manipulam essas substâncias; a ambiental, que ocorre por meio de dispersão/distribuição dos agrotóxicos ao longo dos diversos componentes do meio ambiente; e a alimentar que se dá pela contaminação relacionada à ingestão de produtos contaminados por agrotóxicos (MOREIRA et al.,2002).

Os efeitos à saúde causados pela exposição aos agrotóxicos podem ser agudos ou crônicos. Os efeitos agudos ocorrem a partir de uma única exposição e geralmente em doses altas, já efeitos passam a ser considerados crônicos a partir de exposições a doses baixas ao longo do tempo. Muitas das intoxicações podem provocar diminuição das defesas imunológicas, anemia, impotência sexual, cefaleia, insônia, alterações de pressão arterial, distimia e distúrbios de comportamento (LEVIGARD; ROZEMBERG, 2001).

De acordo com Melo da Silva e Fruchtengarten (2005) apud Marinho (2010), as formas de interação do produto no ambiente acabam alcançando também os trabalhadores do entorno das plantações, trabalhadores das fábricas, trabalhadores do entorno das fabricas, vendedores de lojas que vendem os agrotóxicos, consumidores de alimentos, entre outros.

Uma das problemáticas que vem sendo discutida e pesquisada na atualidade no que tange a exposição dos organismos aos agrotóxicos, refere-se a contaminação por vias indiretas, onde os organismos se expõem aos agrotóxicos por meio de ingestão de água e de alimentos contaminados.

Estudos vem sendo desenvolvidos e comprovam que o manejo adequado de fertilizantes orgânicos pode aumentar a produção em até $40 \%$, mas o uso indiscriminado desses compostos pode acarretar prejuízos ambientais, muitas vezes irreparáveis (VIGNA, 2010).

Quando os agrotóxicos são utilizados em quantidades acima da capacidade de suporte do meio ambiente, divergindo-se de sua finalidade, são capazes de ser quimicamente transformadas quando absorvidas pelas plantas ou por outros organismos do solo e que eventualmente, podem ser ingeridas através dos alimentos podendo também ser transportadas pelas chuvas para os corpos d'água e ainda ser volatilizada para a atmosfera.
A determinação de resíduos de agrotóxicos em alimentos e em amostras ambientais possui importância significativa no controle dos riscos que estes compostos oferecem à saúde humana, além da sua persistência no meio ambiente e tendência de bioacumulação (VIGNA, 2010).

De acordo com o Art. $2^{\circ}$, inciso VI, do Decreto $\mathrm{n}^{\circ}$ 4.074/02, compete a três órgãos federais fazerem o registro dos agrotóxicos de acordo com as exigências e diretrizes previstas por leis, são eles, o Ministério da Agricultura, Pecuária e Abastecimento (MAPA), o Ministério do Meio Ambiente vinculado ao Instituto Brasileiro do meio Ambiente e dos Recursos Naturais e Renováveis (IBAMA) e o Ministério da Saúde (MS) através da Agência Nacional de Vigilância Sanitária (ANVISA).

Quanto à avaliação, classificação toxicológica e monitoramento dos resíduos de agrotóxicos em produtos de origem vegetal, estes são de responsabilidade da ANVISA (ANVISA, 2011). Desde 2008 o Brasil é o maior consumidor de agrotóxicos do mundo, em 2011 foi alcançada a marca de 936 mil toneladas de pesticidas lançados em nossos campos e em 2012 foi ultrapassada a marca de um milhão (CORDEIRO, 2014)

No Brasil, segundo o Sistema Nacional de Intoxicações Toxicológicas - SINITOX, foram notificados em 2009 aproximadamente um total de 11.641 casos de intoxicações agudas por agrotóxicos de uso agrícola, número que pode ser subestimado considerando-se a elevada subnotificação desses eventos no País (CORDEIRO, 2014)

A legislação determina que a aplicação de agrotóxicos no campo só pode ser realizada com o uso dos EPIs (Equipamentos de Proteção Individual) (LONDRES, 2011). No caso dos trabalhadores rurais, os EPIs devem, obrigatoriamente, serem fornecidos pelo empregador em condições adequadas para o uso, e cabe ao empregado usá-lo de modo a minimizar a exposição aos riscos à saúde (BRASIL, 1978).

De acordo com sua composição e finalidade os agrotóxicos são classificados como acaricidas, bactericidas, fungicidas, herbicidas, inseticidas, nematicidas, rodenticidas e moluscicidas (DOMINGUES, 2010). Os herbicidas, por exemplo, representaram $45 \%$ do total de agrotóxicos comercializados, seguidos dos fungicidas com $14 \%$ do mercado nacional, os inseticidas $12 \%$ e as demais categorias de agrotóxicos 29\% (ANVISA, 2012).

A ANVISA, criou em 2001 o Programa de Análise de Resíduos de Agrotóxicos em Alimentos-(PARA), que é um programa a nível nacional que pretende prevenir os riscos humanos relacionados à ingestão de alimentos contaminados. os dados obtidos pelo PARA servem para identificar as fontes de poluição e analisar a qualidade dos alimentos consumidos pela população. Este trabalho passou a ser uma ação do Sistema Nacional de Vigilância Sanitária (SNVS), coordenado pela Anvisa em conjunto com os órgãos de vigilância sanitária de 27 estados. O estado da Paraíba aderiu ao programa PARA desde o ano de 2009.

Para os alimentos de origem vegetal, são préestabelecidos um Limite Máximo de Resíduos (LMR), o qual é a quantidade máxima de resíduos de agrotóxicos ou afins, oficialmente, aceita no alimento, expressa em $\mathrm{mg} / \mathrm{Kg}$. Com isso, é estabelecido um intervalo de segurança de cada ingrediente ativo (IA) ou período de carência que representa o intervalo de tempo entre a última aplicação do agrotóxico e a 
colheita ou comercialização para determinado tipo de cultura, a fim de que os alimentos sejam consumidos com segurança pela população (ANVISA, 2011).

Os relatórios anuais fornecidos pelo Programa são essenciais para indicar se os alimentos comercializados no varejo apresentam níveis de resíduos de agrotóxicos dentro dos LMR determinados pela Anvisa e publicados em monografia específica para cada agrotóxico, aferir se os agrotóxicos utilizados estão devidamente registrados no país e se foram aplicados apenas nas culturas para as quais estão autorizados, estimar a exposição da população a resíduos de agrotóxicos em alimentos de origem vegetal e, consequentemente, avaliar o risco à saúde dessa exposição (ANVISA, 2013).

O objetivo do trabalho foi analisar os dados do relatório PARA de diversos alimentos coletados pela Agência Estadual de Vigilância Sanitária da Paraíba AGEVISA - PB, entre aos anos de 2011 e 2013 e correlacioná-los com as possíveis implicações na saúde da população e no meio ambiente.

\section{MATERIAL E MÉTODOS}

Para o presente estudo foi utilizado o método de pesquisa quantitativo, que é muito utilizado no desenvolvimento das pesquisas descritivas, em que se procura descobrir e classificar a relação entre variáveis, bem como a investigação da relação de causalidade entre fenômenos: causa e efeito (APPOLINÁRIO, 2006).

Foram avaliados os dados referentes aos resíduos de agrotóxicos em quinze diferentes culturas: Abacaxi, Cenoura, Laranja, Pepino, Mamão, Pimentão, Alface, Tomate, Uva, Banana, Cebola, Abobrinha, Maçã, Arroz e Feijão, que foram coletadas em vários supermercados da Paraíba de acordo com princípios e guias internacionalmente aceitos conforme o Codex Alimentarius ou código de alimentos.

As amostras após coletadas foram encaminhadas a laboratórios credenciados, onde a presença de agrotóxicos foi detectada e quantificada.
Foram investigados aproximadamente 234 diferentes ingredientes ativos, cuja metodologia de análise foi realizada por meio do método analítico de "multirresíduos". Este método consiste em analisar simultaneamente diferentes ingredientes ativos de agrotóxicos em uma mesma amostra, sendo ainda capaz de detectar diversos metabólitos. (ANVISA, 2013). Sendo que, a origem do produtor, de mais da metade desses alimentos é do próprio estado da Paraíba.

Os dados analisados foram coletados entre os anos de 2011, 2012 e 2013 e realizou-se uma análise estatística simples utilizando o programa Excel 2007.

A ANVISA classifica os alimentos em: amostras sem resíduos (N); amostras insatisfatórias (I), que correspondem à presença de resíduos de agrotóxicos em culturas para as quais não tinham seu uso autorizado ou a sua quantidade autorizada para determinada cultura encontra-se superior ao Limite Máximo de Resíduos (LMR) permitido; e em "Amostras Satisfatórias com Resíduos (S)", que são consideradas as amostras que continham uma presença de resíduos dentro LMR.

\section{RESULTADOS E DISCUSSÃO}

Os laudos cedidos pela AGEVISA foram analisados quanto as 100 amostras de 15 diferentes culturas, Abacaxi, Cenoura, Laranja, Pepino, Mamão, Pimentão, Alface, Tomate, Uva, Banana, Cebola, Abobrinha, Maçã, Arroz e Feijão.

Na Tabela 1 encontra-se descrito a distribuição e qualidade das amostras analisadas por ano. Esses limites são estabelecidos e regulamentados pela Gerência Geral de Toxicologia (GGTOX/ANVISA), que tem a competência de avaliar e classificar toxicologicamente os agrotóxicos.

A Figura 1 representa uma análise comparativa entre amostras insatisfatórias (I) e satisfatórias com resíduos (S).

Tabela 1 - Distribuição e qualidade das amostras analisadas por ano

\begin{tabular}{cccc}
\hline ANO & $\mathbf{2 0 1 1}$ & $\mathbf{2 0 1 2}$ & $\mathbf{2 0 1 3}$ \\
\hline Total de amostras analisadas por ano & 19 & 64 & 17 \\
Total de amostras satisfatórias com resíduos por ano (S) & 0 & 20 & 2 \\
Total de amostras sem resíduos por ano (N) & 0 & 33 & 12 \\
Total de amostras insatisfatórias por ano (I) & 19 & 11 & 3 \\
\hline
\end{tabular}

Fonte: AGEVISA (2013)

Figura 1. Análise comparativa entre amostras insatisfatórias (I) e amostras satisfatórias com resíduos (S)

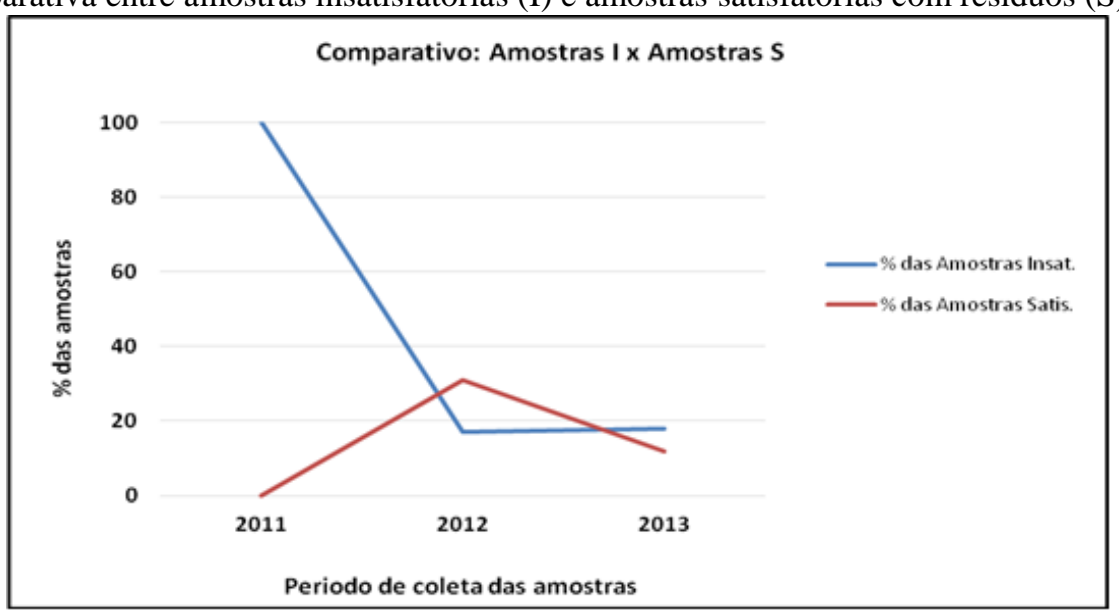


A partir dos resultados obtidos, pode-se observar que todas as amostras de Cenoura, Pepino, Mamão, Pimentão, Alface, Tomate e Uva coletadas no ano de 2011, foram classificadas como insatisfatórias para o consumo humano.

Em três amostras de mamão, foram encontrados onze tipos diferentes de ingredientes ativos, um acima do LMR permitido para a cultura e dois não autorizados para o cultivo do alimento. O pimentão teve sete amostras analisadas em 2011 e todas irregulares, algumas delas com elevado grau de toxicidade aguda comprovada e outras apresentaram substâncias como o Metamidofós e Carbendazim, que estão relacionados à alta toxicidade aguda. Nas 7 (sete) amostras, foram encontrados 9 (nove) tipos de ingredientes ativos diferentes que não são autorizados para a cultura.

Segundo dados da ANVISA de 2008, o ingrediente ativo Metamidofós, encontrado em uma das amostras de pimentão, está em processo de reavaliação aqui no Brasil, mesmo assim continua sendo importado em larga escala, a substância é proibida em vários locais do mundo, como União Européia e China.

O pesticida, Metamidofós, teve indicações de sua proibição no Brasil, e de acordo com Marinho (2010), este contém elevado e comprovado grau de toxicidade que causa problemas para os sistemas reprodutivos, neurológicos, reprodutivos e até câncer. Em seus estudos, Satar et al., (2008) observaram alterações ultraestruturais em tecidos da tireóide de ratos, em decorrência de intoxicações pelo inseticida metamidofós.

Ressalta-se que de todas as culturas analisadas, de acordo com o relatório do PARA de 2011, o pimentão foi o alimento com o maior número de amostras insatisfatórias (80\%). O dado é preocupante, pois em longo prazo essa exposição eleva o risco aos efeitos crônicos, ou aqueles resultantes de uma exposição continuada a doses relativamente baixas de um ou mais produto (PERES; MOREIRA E DUBOIS, 2003).

Outro ponto importante que merece destaque nesta discussão, referente às amostras insatisfatórias que apresentaram níveis de agrotóxicos acima do LMR, consiste da não observância dos agricultores quanto as informações dadas pelos fabricantes presentes nos rótulos e bulas para uma aplicação consciente, e provavelmente também por desconhecer o período de carência entre a última aplicação dos agrotóxicos e a colheita da cultura (PREZA; AUGUSTO, 2012).

Com relação aos resultados insatisfatórios obtidos por meio das análises, estes podem ter ocorrido devido à aplicação de agrotóxicos não autorizados no Brasil ou não autorizados para aquela determinada cultura (ANVISA, 2010).

Entre as 64 amostras analisadas em 2012, 20 destas foram consideradas satisfatórias, uma vez que, apresentavam concentrações de ingredientes ativos, dentro do permitido para o consumo, referente à aquela cultura. Outro dado preocupante é o total de amostras insatisfatórias encontradas em apenas um ano de coleta de alimentos, foram registradas 11 amostras insatisfatórias em 2012.

No ano de 2013 os resultados mostraram que entre as oito amostras de cebola analisadas, três foram consideradas insatisfatórias, decorrentes do uso de Acefato, agrotóxico não autorizado para a cultura. De acordo com Marinho (2010), o Acefato é proibido nas lavouras da Comunidade Européia, pois está relacionado com a neurotoxicidade e toxicidade reprodutiva, causadas aos seres humanos.

Segundo Rodrigues et al.,(2011), o cultivo de cebola é muito vulnerável ao ataque de doenças de origem fúngica, bacteriana, viral e nematológica, desde o cultivo até o consumo. Apesar de ser um alimento que necessite de agrotóxicos para se ter uma boa produção, aumentou-se a quantidade de aplicações de agrotóxicos nas lavouras, isso fez com que em 2008 o alimento fosse incluído na lista do PARA.

Com relação, à cultura do abacaxi, alimento típico, com grandes áreas de plantio no Estado da Paraíba e muito comercializado no mercado interno e externo ao estado paraibano, verificou-se que em quatro amostras foram encontrados problemas. Estas irregularidades correspondem à detecção de resíduos de agrotóxicos de uso não autorizado para a cultura, sendo estes: Procloraz, Bifentrina, Clotianidina e Esfenvalerato.

Estes ingredientes ativos como, por exemplo, o Procloraz, é considerado como um desregulador endócrino que diminui a produção e síntese de hormônios corticosteroides, prejudicando a fertilidade masculina, o metabolismo de nutrientes e a regulação do sistema imunológico (KJAERSTAD et al., 2010; HIGLEY et al., 2010).

Em sua pesquisa Lins (2013), buscando correlacionar os resultados do monitoramento do PARA na Paraíba, com ênfase na cultura do abacaxi, observou por meio da aplicação de questionários estruturados em uma cooperativa de agricultores, que o manuseio e aplicação dos agrotóxicos era feito com irregularidades, como por exemplos: o uso de produtos não autorizados para a cultura do abacaxi, sendo estes permitidos para a cultura de cana-deaçúcar, a utilização parcial dos EPIs e o descarte incorreto das embalagens vazias no ambiente. Como consequências para o meio ambiente, o solo segundo os produtores representa o recurso natural mais afetado, com efeitos sobre as propriedades físico-químicas e sua fertilidade.

A presença de resíduos de agrotóxicos na água ocasiona a mortandade de plantas e animais, câncer, tumores e lesões em peixes e outros animais, problemas de reprodução, alterações genéticas, disrupção endócrina e do sistema imunológico (como ocorre em humanos), dentre outras consequências (CORDEIRO, 2014).

Diante do exposto verificou-se que, a falta de orientação técnica dos produtores durante o manuseio e aplicação dos agrotóxicos para eliminação de pragas e ervas daninhas presentes em suas lavouras, acabam por colocar em risco os sistemas produtivos locais, meio ambiente e, sobretudo a saúde da população, e particularmente dos próprios agricultores que são as pessoas mais expostas a contaminação.

Esses dados destacam a importância de uma investigação mais detalhada para algumas culturas analisadas, dentre elas a cultura do abacaxi, por ser um alimento muito consumido pelos brasileiros, em especial a população nordestina, e que pode estar causando efeitos tóxicos à saúde humana, além de ser uma cultura bastante vulnerável a doenças, demandando quantidades cada vez maiores de agrotóxicos.

Das 81 amostras analisadas entre os anos de 2012 e 2013, cerca de $18 \%$ foram consideradas insatisfatórias, 
ocorrendo uma grande queda do número de alimentos contaminados em relação ao ano anterior de 2011 que teve $100 \%$ de suas amostras insatisfatórias (I).

Apesar do número preocupante nos anos de 2012 e 2013 de amostras insatisfatórias, ainda assim observou-se uma redução dos índices de amostras contaminadas em relação às amostras de 2011, justificativas foram, portanto, levantadas pela equipe de pesquisadores, como por exemplo: ocorrência de fiscalizações mais rigorosas sob responsabilidade dos órgãos responsáveis no setor alimentício, visto que a ANVISA começou a análise de agrotóxicos em alimentos no ano de 2001, e o estado da Paraíba aderiu a este programa a partir de 2009.

Outros motivos para essa queda que chega a $82 \%$ podem estar associados a uma maior orientação agronômica dos trabalhadores do campo na aplicação dos produtos, fiscalização na compra exigindo assim um receituário agronômico, maior fiscalização na reavaliação dos ingredientes ativos quando surgem ocorrências de riscos que podem suspender o uso de produtos registrados e pelo cumprimento do período de carência entre a última aplicação dos agrotóxicos e a comercialização do produto.

É importante destacar que a utilização dos agrotóxicos esta diretamente relacionada com as diversas modificações na agricultura. Por meio do uso da tecnologia, originou um intenso aumento de produtos sintéticos, que por sua vez, tem contribuído com diversos impactos negativos ao meio ambiente, dentre eles, poluição das águas, danos a diversas espécies de animais, interferindo também saúde dos seres humanos (OLIVEIRA, et al., 2013; CORDEIRO, 2014).

Cruz (2014), destaca em sua pesquisa, alguns sistemas de produção de alimentos de menores riscos de contaminação por agrotóxicos, dentre estes estão: a agricultura orgânica, a produção integrada e o cultivo por meio de agricultura de precisão. Os três sistemas representam os principais modelos de produção de alimentos compostos de técnicas de manejo capazes de prover alimentos mais seguros e com equilíbrio nos compartimentos ambientais.

Nesse sentido, é perceptível uma melhoria significativa na qualidade dos alimentos advindos de um sistema de produção agroecológica, o que contribui para a comercialização de alimentos saudáveis para a população sem comprometer a dinâmica dos ciclos da própria natureza.

\section{CONCLUSÕES}

Os resultados apresentados alertam para um quadro preocupante e silencioso na nossa rotina diária, visto que ha uma fragilidade social e ambiental aos agrotóxicos, indicando a necessidade de implementar agendas específicas de políticas públicas e ações no campo da saúde, do meio ambiente sustentável e da educação do trabalhador agrícola.

Esses dados são de interesse social, devido aos quinze alimentos analisados apresentarem alguma irregularidade em relação à presença de resíduos de agrotóxicos.

Cabe aos órgãos responsáveis pela capacitação, trazer as informações para os agricultores de todo o país, difundindo boas práticas agrícolas na sua formação, para uma melhor manipulação e aplicação dos produtos, assim como aumentar a fiscalização.
A divulgação dos resultados sobre a presença de agrotóxicos nos alimentos que são consumidos, e sobre os perigos a eles associados, vem cumprindo um importante papel de incentivar e estimular um conjunto de ações com parcerias, com o objetivo principal de melhorar a qualidade e a segurança dos alimentos.

Com isso, são de suma importância os estudos que identificam os impactos resultantes do uso dos agrotóxicos tanto no âmbito de saúde pública como para o ambiente, uma vez que, ambiente e saúde devem estar interligados na busca por soluções mais sustentáveis principalmente seguindo as bases e princípios da agroecologia.

\section{REFERÊNCIAS BIBLIOGRÁFICAS}

ANVISA - Agência Nacional de Vigilância Sanitária. Seminário volta a Discutir Mercado de Agrotóxicos em 2012, Brasília; 2012. Disponível em: <http://portal.anvisa.gov.br> Acesso em: 26 nov. 2014.

ANVISA. Programa de Análise de Resíduos de Agrotóxicos em Alimentos - PARA. Relatório de Atividades de 2010. Gerência Geral de Toxicologia. Brasília, 05 de dezembro de 2011. Disponível em www.anvisa.gov.br, acessado em 01 out 2013.

ANVISA. Programa de Análise de Resíduo de Agrotóxico em Alimentos (PARA), dados da coleta e análise de alimentos de 2010, ANVISA, dezembro de 2011. Disponível em www.anvisa.gov.br, acesso em: 01 out 2013.

ANVISA. Programa de Análise de Resíduos de Agrotóxicos em Alimentos - PARA. Relatório de Atividades de 2011 e 2012. Gerência Geral de Toxicologia. Brasília, 29 de outubro de 2013. Acesso em: 25 nov 2014.

APPOLINÁRIO, F. Metodologia da Ciência: filosofia e prática da pesquisa. São Paulo: Pioneira Thomson Learning, 2006. p. 59-70.

BRASIL, Portaria GM n. ${ }^{\circ}$ 3.214, de 08 de junho de 1978. NR-6, Equipamentos de Proteção Individual - EPI. Ministério do Trabalho e Emprego, Brasília 06, jul, 1978.

BRASIL. Decreto $n^{0} \mathbf{4 . 0 7 4}$ de 04 de janeiro de 2002. Regulamenta a Lei $n^{\circ} 7.802 / 89$ que dispõe sobre a pesquisa, a experimentação, a produção, a embalagem e rotulagem, o transporte, o armazenamento, a comercialização, a propaganda comercial, a utilização, a importação, a exportação, o destino final dos resíduos e embalagens, o registro, a classificação, o controle, a inspeção e a fiscalização de agrotóxicos, seus componentes e afins, e dá outras providências. Diário Oficial da União, Brasília, DF, 08 de jan de 2002.

CORDEIRO, T. A. O que você precisa saber sobre a água de João Pessoa. Editora Ideia, João Pessoa, 2014, 196 p.

CRUZ, G. V. O quadro de contaminação de frutas, legumes e verduras (FLVs) com resíduos de 
agrotóxicos no Brasil e as oportunidades emergentes. Dissertação (Mestrado em Agronegócios). Porto Alegre, UFRS, 2014, 135 p.

DOMINGUES, E. Sistema de Informação Geográfica e a Contaminação de Agrotóxicos no Meio Ambiente da Cana-de-Açúcar na Bacia Hidrográfica do Rio Pardo - SP/MG. Tese (Doutorado em Geografia). Universidade Estadual Paulista, São Paulo, 2010, 149 p.

HIGLEY, E. B.; NEWSTED, J. L.; ZHANG, X.; GIESY, J. P; HECKER, M. Assessment of chemical effects on aromatase activity using the $\mathbf{H 2 9 5 R}$ cell line. Environ Sci Pollut Res Int. v.17, p.5, 2010, p.1137- 48.

KJAERSTAD, M.B.; TAXVIG, C.; NELLEMANN, C.; VINGGAARD, A. M; ANDERSEN, H. R. Endocrine disrupting effects in vitro of conazole antifungals used as pesticides and pharmaceuticals. Reprod Toxicol. v.30, n.4, 2010, p.573-82.

LEVIGARD, Y. E.; ROZEMBERG, B. A interpretação dos profissionais de saúde acerca do nervoso no meio rural. Dissertação submetida à Escola Nacional de Saúde Publica. Centro de Estudos da Saúde do Trabalhador e Ecologia Humana. Fundação Oswaldo Cruz, Rio de Janeiro - RJ, 2001.

LIMA, N. C. Avaliação do impacto da contaminação do colo de áreas agrícolas de bom repouso (MG) por meio de ensaios ecotoxicológicos. Dissertação (Mestrado em Ciências da Engenharia Ambiental), São Paulo, 2010, 130 p.

LINS FILHO, L. A. L. Análise dos Resíduos de Agrotóxicos em Abacaxi: Implicações no Meio Ambiente e Saúde. Trabalho de Conclusão do Curso (Graduação em Engenharia Ambiental). Universidade Federal da Paraíba. João Pessoa, 2013, 53 p.

LONDRES, F. Agrotóxicos no Brasil: um guia para ação em defesa da vida. Rio de Janeiro: AS-PTA Assessoria e Serviços a Projetos em Agricultura Alternativa, $1^{\mathrm{a}}$. edição, 2011, 190 p.

MARINHO, A. M. C. P. Contextos e contornos da modernização agrícola em municípios do Baixo Jaguaribe-CE: $O$ Espelho do (des)envolvimento e seus reflexos na saúde do trabalho e ambiente. Tese (Doutorado em Saúde Pública), São Paulo-SP, 2010, $244 p$.

MONQUERO, P. A., INÁCIO, E. M., SILVA, A. C. Levantamento de Agrotóxicos e Utilização de Equipamento de Proteção Individual entre os Agricultores da Região de Araras. Arq. Inst. Biol., São Paulo, v.76, n.1, p.135-139, jan./mar., 2009.

MOREIRA, J. C.; JACOB, S. C.; PERES, F. Avaliação integrada do impacto do uso de agrotóxicos sobre a saúde humana em uma comunidade agrícola de Nova Friburgo, RJ. Ciência e Saúde Coletiva. 2002; 7(2): p. 299-311.
OLIVEIRA, T. G., FAVARETO, A. P. A., ANTUNES, P. A Agrotóxicos: Levantamento dos mais Utilizados no Oeste Paulista e seus Efeitos como Desreguladores Endócrinos. IX Fórum Ambiental da Alta Paulista. Saúde, Saneamento e Meio Ambiente. V.9, n.11, p. 375390, 2013.

PERES, F.; MOREIRA, J. C.; DUBOIS, G. S. É veneno ou é remédio? Agrotóxicos, Saúde e Ambiente. Rio de Janeiro. Ed. FIOCRUZ. Parte I, cap. 1, 2003, p. 21-41.

PREZA, D. L. C.; AUGUSTO, L. G. S. Vulnerabilidades de trabalhadores rurais frente ao uso de agrotóxicos na produção de hortaliças em região do Nordeste do Brasil. Ciência e Saúde Coletiva. V. 37 n. 125, 2012, p. 89-98.

RODRIGUES, S. A.; CALDAS, S. S.; FURLONG, E. B.; PRIMEL, E. G.; ZANELLA' R. "Otimização e validação de método empregando QuEChERS modificado e LC-ESI-MS/MS para determinação de agrotóxicos em cebola." Quim. Nova, v. 34, n.5, São Paulo, 2011, p.780-786.

SALEM, R. E. P., MOURA, L. F. A utilização de equipamentos de proteção individual (EPIs) na manipulação de agrotóxicos: análise sob os aspectos legais e ergonômicos. IV CONGRESSO BRASILEIRO DE ENGENHARIA DE PRODUÇÃO. Ponta Grossa, PR, Brasil, dez de 2014.

SATAR, D.D.; SATAR, S.; METE, U.O.; SUCHARD, J.R.; TOPAL, M.; KARAKOC, E.; KAYA, M. Ultrastructural changes in rat thyroid tissue after acute organophosphate poisoning and effects of antidotal therapy with atropine and pralidoxime: a single-blind, ex vivo study. Current therapeutic research, v. 69, n. 4, 2008.

SINITOX- Sistema Nacional de Informações TóxicoFarmacológicas. Casos registrados de intoxicação humana por agente e por região, Brasil. 2011. $<$ http://www.fiocruz.br/sinitox_novo/media/Tabela\%20 3.pdf> Acesso em: 26 mai. 2014.

SINHA, S. N.; BHATNAGAR, V. K.; DOCTOR, P.; TOTEJA, G. S.; AGNIHOTRI, N. P.; KALRA, R. L. A Novel Method for Pesticide Analysis in Refined Sugar Samples Using a Gas Chromatography-Mass Spectrometer (GC-MS/MS) and Simple Solvent Extraction Method. Food Chemistry, v.126 p. 379 386, 2011.

VIGNA, C. R. M. Aplicação de Polissiloxanos Imobilizados sobre Sílica como Fase Estacionária e como Sorvente na Determinação de Agrotóxicos em Água e Caldo de Cana. Tese (Doutorado em Química). Universidade Estadual de Campinas, Instituto de Química, CampinasSP, 2010, 137 p. 